\title{
Evaluation of the immunogenicity of a recombinant HSV-1 vector expressing human group C rotavirus VP6 protein
}

\author{
Rosana P. Rota ${ }^{\mathrm{a}}$, Carlos A. Palacios ${ }^{\mathrm{b}}$, C. Facundo Temprana ${ }^{\mathrm{a}, \mathrm{c}}$, Marcelo H. Argüelles ${ }^{\mathrm{a}}$, \\ Marcelo G. Mandile ${ }^{\mathrm{a}, \mathrm{c}}$, Nora Mattion ${ }^{\mathrm{b}}$, Andrea S. Laimbacher ${ }^{\mathrm{d}}$, Cornell Fraefel ${ }^{\mathrm{d}}$, \\ Alejandro A. Castello ${ }^{a}$, Graciela Glikmann ${ }^{\mathrm{a}, *}$ \\ a Laboratorio de Inmunología y Virología, Departamento de Ciencia y Tecnología, Universidad Nacional de Quilmes, Roque Sáenz Peña 352, B1876BXD, Bernal, Buenos \\ Aires, Argentina

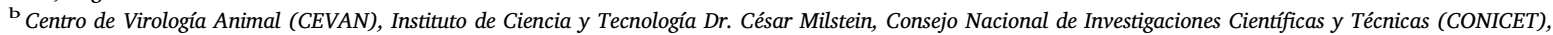 \\ Saladillo 2468, C1440FFX, Ciudad de Buenos Aires, Argentina \\ c Consejo Nacional de Investigaciones Científicas y Técnicas (CONICET), Buenos Aires, Argentina \\ ${ }^{\mathrm{d}}$ Institute of Virology, University of Zurich, Winterthurerstrasse 266a, CH-8057, Zurich, Switzerland
}

\section{A R T I C L E I N F O}

\section{Keywords:}

Rotavirus

VP6

HSV amplicon vector

\begin{abstract}
A B S T R A C T
Group C Rotavirus (RVC) has been associated globally with sporadic outbreaks of gastroenteritis in children and adults. RVC also infects animals, and interspecies transmission has been reported as well as its zoonotic potential. Considering its genetic diversity and the absence of effective vaccines, it is important and necessary to develop new generation vaccines against RVC for both humans and animals. The aim of the present study was to develop and characterize an HSV-1-based amplicon vector expressing a human RVC-VP6 protein and evaluate the humoral immune response induced after immunizing BALB/c mice. Local fecal samples positive for RVC were used for isolation and sequencing of the vp6 gene, which phylogenetically belongs to the I2 genotype. We show here that cells infected with the HSV[VP6C] amplicon vector efficiently express the VP6 protein, and induced specific anti-RVC antibodies in mice immunized with HSV[VP6C], in a prime-boost schedule. This work highlights that amplicon vectors are an attractive platform for the generation of safe genetic immunogens against RVC, without the addition of external adjuvants.
\end{abstract}

\section{Introduction}

Rotaviruses (RV), an important genus of the Reoviridae family, are responsible for most viral diarrhea cases occurring in young humans and animals. These viruses have been classified into different groups based on the antigenic properties or the amino acid sequences of the structural protein VP6 (Estes and Greenberg, 2013), although a full genome-based classification has been proposed recently (Matthijnssens et al., 2008; Patton, 2012). With regards to VP6-based classification, eight groups of RV have been defined (A to H) (Matthijnssens et al., 2012).

Rotaviruses from groups A, B, C, and $\mathrm{H}$ have been associated with human infections, with group A being the most epidemiologically important worldwide (Patton, 2012). Fortunately, the two currently licensed vaccines prevent severe diarrhea associated with group A RV (RVA) reducing its impact and mortality rates, even considering a variable efficacy in developing countries (Bucardo and Nordgren, 2015;
Karafillakis et al., 2015).

Group C RV (RVC) has been demonstrated to contribute to sporadic outbreaks and endemic gastroenteritis in children older than those infected with RVA (4-7 years) and adults. However, identification of RVC has been less common than RVA. A possible cause might be associated with the lack of simple diagnostic tools and the fact that it usually infects older patients who, depending on the severity of clinical symptoms, do not necessarily attend to a medical care center where a correct diagnosis can be made (Baek et al., 2013; Castello et al., 2009; Luchs and do Carmo Sampaio Tavares Timenetsky, 2014; Tiku et al., 2017).

Different studies worldwide have demonstrated that the seroprevalence for RVC is between 30 and $60 \%$. Nevertheless, detection rates in stool samples remain as low as 3\% (Castello et al., 2009; Ishimaru et al., 1990; Nilsson et al., 2000; Steele and James, 1999). Particularly, in a study carried out over four years (1997-2000) in Argentina, half of the studied population had antibodies against RVC (Castello et al., 2002). Although, neither the overall disease burden nor

\footnotetext{
* Corresponding author.

E-mail address: gglikman@unq.edu.ar (G. Glikmann).
} 
the epidemiology of this group of rotaviruses is yet entirely clear, RVC infection has been described in numerous countries, showing epidemiological importance as an emerging human pathogen (Araújo et al., 2011; Castello et al., 2009; Luchs and do Carmo Sampaio Tavares Timenetsky, 2014; Tiku et al., 2017).

The RVC mainly infects animals, being porcine species the most frequently reported host (Vlasova et al., 2017; Wakuda et al., 2011), although evidence of transmission was reported in Brazil, from infected pigs to humans, suggesting a zoonotic potential for this virus (Gabbay et al., 2008). Furthermore, the presence of RVC has been published recently in companion animals, such as cats and dogs (Marton et al., 2015b; Otto et al., 2015). Considering that interspecies transmission events have been previously described (Chang et al., 1999; Jeong et al., 2009), the emergence of RVC reassortants presenting higher infectivity for humans cannot be underestimated (Marton et al., 2015a; Vlasova et al., 2017).

Considering that there are few studies on this particular virus, it is important to develop and analyze different strategies that can eventually be applied to immunize both humans and animals against RVC. In this sense, a classical approach would be the immunization with complete viral particles, whether inactivated or attenuated. However, RVC has been difficult to propagate in cell culture (Saif et al., 1988; Shinozaki et al., 1996; Tsunemitsu et al., 1991), impairing the development of vaccines as well as diagnostic tools. Thus, alternatives that can overcome this problem need to be addressed. To face this issue, Clark et al., (2009) reported the generation of RVC VP6 virus-like particles (VLP) using the baculovirus recombinant technology, which efficiently induced specific antibody responses in rabbits. However, there are some limitations associated with the baculovirus system, which includes the need to use several purification steps and the rather low quantity of correctly assembled VLP obtained from infected insect cells (Kim et al., 2002; Peixoto et al., 2007).

In this sense, herpes simplex virus type 1 (HSV-1)-based vectors represent an attractive gene delivery system, which has not been previously studied as a carrier for RVC antigenic sequences. HSV-1 amplicon vectors have a large transgene capacity (up to $150 \mathrm{kbp}$ ), which allows the encapsidation of multiple genes or multiple copies of a transgene. Moreover, these vectors present (i) low toxicity and immunogenicity, (ii) high in vivo transduction efficiencies, both in quiescent and proliferating cells from most mammalian species including antigen presenting cells, (iii) genetic stability, and (iv) strong adjuvant effects inducing both humoral and cellular immune responses as well as mucosal immunity (de Silva and Bowers, 2009; Epstein, 2009; Laimbacher and Fraefel et al., 2014).

In this work, the generation of an HSV-1 amplicon vector encoding the VP6 protein from an Argentinean human RVC isolate and the analysis of its immunogenic potential in mice is described.

\section{Materials and methods}

\subsection{Viruses}

Human stool samples $(\mathrm{n}=2231)$ collected between 1997 and 2006 were screened for RVC and RVA using in-house developed enzyme immunoassays (EIA) as previously described by Castello et al., (2000) and Argüelles et al., (2000), respectively. Samples positive for RVC and negative for RVA were selected for viral RNA extraction.

\subsection{Genomic RNA extraction and cDNA synthesis}

RVC positive fecal samples were diluted to $20 \% \mathrm{w} / \mathrm{v}$ in phosphate buffered saline (PBS), and $100 \mu \mathrm{l}$ of the obtained suspension were

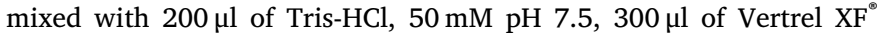
(DuPont Chemicals, Wilmington, DE). After 1-min homogenization, samples were sedimented by low-speed centrifugation. A $200 \mu \mathrm{l}$ aliquot of the aqueous phase was recovered and mixed with $400 \mu$ of lysis buffer (guanidine isothiocyanate $4 \mathrm{M}$, EDTA $0.02 \mathrm{M}$, Triton X-114 $0.01 \% \mathrm{v} / \mathrm{v}$ ) and $40 \mu \mathrm{l}$ of a silica suspension (in $\mathrm{HCl} 0.1 \mathrm{~N}$ ). After $15 \mathrm{~min}$ incubation at room temperature with constant stirring, the samples were centrifuged for $1 \mathrm{~min}$ at $580 \mathrm{~g}$, and the pellet washed first with $600 \mu \mathrm{l}$ of a guanidine isothiocyanate $4 \mathrm{M}$, EDTA $0.02 \mathrm{M}$ solution and then washed three times with ethanol $70 \% \mathrm{v} / \mathrm{v}$. After centrifugation at $9,280 \mathrm{~g}$ for $2 \mathrm{~min}$, the supernatant was discarded, the pellet was dried for $15 \mathrm{~min}$ at room temperature, and the dsRNA was resuspended in $35 \mu \mathrm{l}$ of sterile water. The sample was incubated for $10 \mathrm{~min}$ at $65^{\circ} \mathrm{C}$, centrifuged at $9,280 \mathrm{~g}$ for $2 \mathrm{~min}$ to remove the silica, and the supernatant containing dsRNA was recovered and stored at $-80^{\circ} \mathrm{C}$ until further use.

A 3- $\mu$ l aliquot of the extracted dsRNA was used as the template for reverse-transcription to synthesize cDNA copies from both strands. Briefly, RNA was denatured at $95^{\circ} \mathrm{C}$ for $5 \mathrm{~min}$ and then incubated on ice for $5 \mathrm{~min}$ before this template was mixed with $22 \mu \mathrm{l}$ of the reaction mixture. The final mixture contained $500 \mu \mathrm{M}$ of dNTPs (Promega, USA); $0.4 \mu \mathrm{M}$ random primers; $7 \mathrm{U}$ of AMV reverse transcriptase and $1 \mathrm{X}$ buffer (Promega, USA); $20 \mathrm{U}$ of RNasin RNase inhibitor (Promega, USA) and $5 \% \mathrm{v} / \mathrm{v}$ dimethyl sulfoxide (DMSO) in a final $25 \mu \mathrm{l}$ volume. Synthesis of the corresponding cDNA was performed for $2 \mathrm{~h}$ at $42^{\circ} \mathrm{C}$ in a Biometra T gradient thermocycler (Biometra $\mathrm{GmbH}$, Germany).

\subsection{Cloning of the human RVC VP6 coding sequence}

Human RVC (hRVC) VP6 oligonucleotide primers were designed based on reference RVC VP6 gene sequences, obtained from the GenBank database. These primers were: Fwd-VP6-C1 5'-CTCATTCACA ATGGATGTACT-3' and Rev-VP6-C2 5'-CTAGCTTATCTACATTACC-3'. The VP6 open reading frame was PCR amplified at the following conditions: one cycle at $95^{\circ} \mathrm{C}$ for $2 \mathrm{~min} ; 35$ cycles of $94^{\circ} \mathrm{C}$ for $10 \mathrm{~s}, 52^{\circ} \mathrm{C}$ for $15 \mathrm{~s}, 72^{\circ} \mathrm{C}$ for $90 \mathrm{~s}$; and a final cycle at $72{ }^{\circ} \mathrm{C}$ for $10 \mathrm{~min}$.

The amplification product (1206 bp) was purified from the gel with QIAquick Gel Extraction Kit (QIAGEN GmbH, Germany) and ligated into pGEM-T (Promega, USA) according to the manufacturer's instructions. The ligation product was used to transform electrocompetent TOP10 E. coli cells, as previously described (Sambrook et al., 1989). Colony PCR screening was performed using the Fwd-VP6-C1 and RevVP6-C2 primers, and positive clones were sent for sequencing (Macrogen Inc., Seoul, South Korea).

\subsection{VP6 phylogenetic analysis}

Evolutionary relationships between previously reported human, swine and bovine VP6 RVC sequences, and the one obtained in this study were evaluated. Multiple sequence alignment was performed with Clustal_X 2.1 software (Larkin et al., 2007), and phylogenetic analysis was conducted using MEGA v6.06 (Tamura et al., 2013).

A phylogenetic dendrogram was constructed using nucleotide sequence alignments, by the neighbor-joining algorithm based on Kimura-2 parameter distance matrix, with 1000 bootstrap replications. Furthermore, the evolutionary divergence based on nucleotide and amino acid sequences was also estimated. The analysis of the number of base substitutions per site was conducted using the Maximum Composite Likelihood model. Codon positions included were $1 \mathrm{st}+2 \mathrm{nd}$ $+3 \mathrm{rd}+$ Noncoding, and there was a total of 1123 positions in the final dataset. The number of amino acid substitutions per site was analyzed using the Poisson correction model. There was a total of 370 positions in the final dataset. Both evolutionary analyses were conducted using MEGA v6.06, and all positions containing gaps and missing data were eliminated.

\subsection{Nucleotide sequence accession number}

The nucleotide sequence of the VP6 gene reported in this study was submitted to GenBank, and the assigned accession number is 
MF422080.

\subsection{Amplicon plasmid construction}

Amplicon plasmid was constructed using the previously described pHSVs system (D'Antuono et al., 2010; Laimbacher and Fraefel et al., 2014). Briefly, the transgene expression is supported by the HSV-1 IE4/ 5 promoter, followed by a viral internal ribosomal entry site (IRES) which controls the EGFP reporter gene expression. The plasmid also contains two HSV-1 functional sequences: the ori and the pac signal, which support the replication of the amplicon DNA and packaging into HSV-1 particles in the presence of HSV-1 helper functions. For prokaryotic propagation, the amplicon plasmid contains an ampicillin resistance gene and colE1 replication origin. The VP6C open reading frame was excised from the recombinant plasmid pGEM/VP6C and inserted into $S b f \mathrm{I}$ and $H s p 92 \mathrm{I}$ restriction sites of $p H S V s$, generating the pHSV/HVP6C amplicon plasmid.

\subsection{Cells}

Vero 2-2 cells (Smith et al., 1992) were propagated in Dulbecco's modified Eagle medium (DMEM, Life Technologies, CA, Carlsbad, USA) supplemented with $10 \% \mathrm{v} / \mathrm{v}$ fetal bovine serum (FBS. Internegocios SA, Argentina), penicillin $\mathrm{G}(100 \mathrm{U} / \mathrm{ml})$, streptomycin $(100 \mu \mathrm{g} / \mathrm{ml})$ and Geneticin $^{\circ}(500 \mu \mathrm{g} / \mathrm{ml}$, Life Technologies, CA, Carlsbad, USA), and maintained at $37^{\circ} \mathrm{C}$ in a $5 \% \mathrm{CO}_{2}$ atmosphere.

\subsection{Amplicon vector preparation}

Amplicon vector stocks were prepared as previously described (Laimbacher et al., 2012; Laimbacher and Fraefel et al., 2014; De Oliveira et al., 2008; Saeki et al., 2001). Briefly, in order to obtain the amplicon vector stocks, Vero 2-2 cells were co-transfected with the amplicon plasmid, a bacterial artificial chromosome containing the replication-competent and packaging-defective HSV-1 genome (fHSV $\Delta$ pac $\Delta \mathrm{ICP} 27$ ), and the pEBHICP27 plasmid which provides ICP27 in trans using Lipofectamine ${ }^{\mathrm{TM}}$ and Plus ${ }^{\mathrm{TM}}$ Reagent (Life Technologies, CA, Carlsbad, USA), following manufacturer's instructions. Seventy-two hours post-transfection, cells were scraped off into the medium and supernatant was recovered by centrifugation at $2000 \mathrm{~g}$ for $5 \mathrm{~min}$ at $4^{\circ} \mathrm{C}$. Titers of amplicon vectors were determined in Vero 2-2 cells, by scoring the number of GFP positive cells under a fluorescence microscope (Axio Observer inverted microscope; Zeiss AG, Feldbach, Switzerland), after $24 \mathrm{~h}$ post-transduction. Titer was expressed as transducing units per milliliter (TU/ml).

\subsection{Immunofluorescence assays}

Vero 2-2 cells were grown on 12-mm glass coverslips in 24-well cell culture plates and transduced with HSV-hVP6C amplicon vector at a $50-60 \%$ cell confluence with an MOI of $0.5 \mathrm{TU} /$ cell. Infected and noninfected (control) cells were washed with PBS and then incubated in fixation solution (3.7\% v/v formaldehyde in PBS) for $15 \mathrm{~min}$ at room temperature. After a 5-min treatment with $0.1 \mathrm{M}$ glycine in PBS, cells were permeabilized with PBS-T $(0.2 \% \mathrm{v} / \mathrm{v}$ Triton $\mathrm{X}-100$ in PBS). Blocking was performed with PBS-BSA ( $3 \% \mathrm{w} / \mathrm{v}$ bovine serum albumin in PBS). To detect recombinant hRVC VP6 protein cells were incubated for one $\mathrm{h}$ at $37^{\circ} \mathrm{C}$ in a humidity chamber with anti- VP6 (Cowden strain) rabbit IgG (kindly provided by Dr. Cohen, Virologie Moleculaire et Structurale, Cédex, France) as primary antibody diluted in PBS-BSA (1:400). After three washes with PBS a 1:400 dilution of goat antirabbit IgG(H + L)-Alexa Fluor 594 (Molecular Probes, Invitrogen, USA) secondary antibody was added and incubated for one $\mathrm{h}$ at $37^{\circ} \mathrm{C}$ in a humidity chamber. After three washes with PBS, cell nuclei were stained with DAPI $(1 \mu \mathrm{g} / \mathrm{ml}$ in PBS; Roche, Switzerland). After the washing steps, coverslips were mounted in Glycergel (Dako
Cytomation, Denmark) containing $25 \mathrm{mg} / \mathrm{ml}$ DABCO (Sigma-Aldrich) to retard discoloration. Samples were analyzed using a confocal laserscanning microscope SP2 (Leica Microsystems, Wetzlar, Germany, 63 $\mathrm{X} / 80 \mathrm{X}$ oil objective).

For comparison purposes, the same procedure was performed by transduction of Vero 2-2 cells with HSV-hVP6A amplicon vector (expressing VP6 protein from human group A, rotavirus strain Wa). For hRVA VP6 detection permeabilized cells were probed with the monoclonal antibody 2F diluted in PBS-BSA (1:2000), followed by incubation with Alexa Fluor 594-conjugated goat anti-mouse IgG antibody (1:1000) (Palacios et al., 2015).

\subsection{Western blot}

Vero 2-2 cells and HSV-hVP6A transduced cells, were washed with PBS, lysed with 5X Laemmli buffer, and the protein extracts were separated by SDS-polyacrylamide gel electrophoresis. Proteins were transferred onto a PVDF membrane and after blocking with PBS-T containing $1 \% \mathrm{w} / \mathrm{v}$ casein (PBS-TC), probed ON at $4{ }^{\circ} \mathrm{C}$ with biotinylated rabbit anti-VP6 (Cowden strain) IgG in PBS-TC (1:200). After washing, the membrane was incubated with HRP-streptavidin (1:2500 dilution; Dako, Denmark) in PBS-TC, followed by detection with a chemiluminescent substrate (Kalium Technologies, Bernal, Argentina) according to manufacturer's instructions. As negative controls, untransduced cells and cells transduced with an unrelated amplicon vector HSV[MSP5], coding for Anaplasma marginale MSP5 antigen were used (Palacios et al., 2014).

\subsection{Mouse immunization and sample collection}

Three groups of six mice each (8-week old male BALB/c mice), previously confirmed to be negative for anti-RV antibodies by EIA, were immunized subcutaneously three times (on days 0,28 , and 42) using $1 \times 10^{6}$ TU of HSV-hVP6C amplicon vector per dose, PBS or HSV-EGFP $\left(1 \times 10^{6} \mathrm{TU}\right)$ as control groups. Blood samples were collected on days 0,28 and 42 before each immunization and a final sample was obtained on day 56 . Sera were recovered and stored individually at $-20^{\circ} \mathrm{C}$ until use. All animal procedures were conducted according to the Universidad Nacional de Quilmes Ethics Committee regulations.

\subsection{EIA analysis of mouse sera}

The humoral immune response was evaluated by an in-house EIA. Briefly, capture antibody [rabbit anti-RVC VP6 (Cowden strain) serum] was immobilized onto EIA 96-well plates overnight at $4{ }^{\circ} \mathrm{C}$ in carbonate buffer. A previously calibrated dilution of a pool of RVC positive stool samples (Castello et al., 2002), were incubated in PBS-TC for one $\mathrm{h}$ at $37^{\circ} \mathrm{C}$ in a humidity chamber. Stool samples positive for RVA and negative for RVC were used to set blank. After washing three times with PBS-T, the collected mouse sera were tested in a 1:100 dilution (in PBS$\mathrm{TC}$ ), and plates were incubated for one $\mathrm{h}$ at $37^{\circ} \mathrm{C}$. Finally, HRP-conjugated goat anti-mouse IgG (DAKO, Denmark) was added to the plates for one $\mathrm{h}$ at $37^{\circ} \mathrm{C}$. Plates were washed three times with PBS-T, and the o-phenylenediamine substrate was used for detection. The reaction was stopped after $15 \mathrm{~min}$ with sulfuric acid, and the $\mathrm{OD}_{490 \mathrm{~nm}}$ was determined. The cut-off value for this assay was calculated as 0.589 $\mathrm{OD}_{490 \mathrm{~nm}}$. For titration of specific RVC IgG, sera from groups immunized with HSV- hVP6C or HSV-EGFP were two-fold serially diluted and evaluated as mentioned above. The titer was informed as the reciprocal of the last positive dilution.

\subsection{Statistics}

Statistics were performed with GraphPad Prism software (La Jolla, $\mathrm{CA}$ ) and the results are expressed as the mean \pm standard deviation (SD). The statistical tests used are mentioned in the figure captions. 


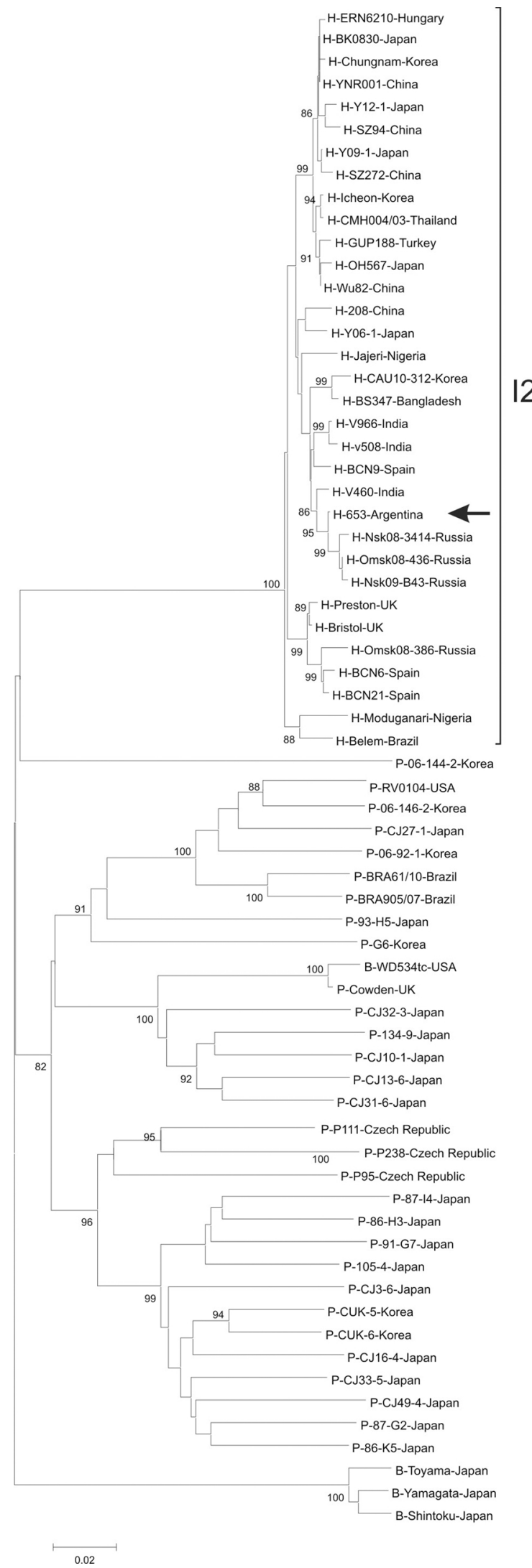

Fig. 1. Phylogenetic dendrogram of RVC vp6 genes constructed by the neighbor-joining method using the MEGA v6.06 software. Numbers shown at the branch nodes indicate the bootstrap values (values $<80$ were not included); the genotype is shown on the right side. The sequence obtained in this study is (H-653-Argentina) is marked with a black line at the right.
Table 1

Average identity in nucleotide and amino acid sequences of Argentinian hRVC VP6 and 66 humans, porcine or bovine strains.

\begin{tabular}{llll}
\hline $\begin{array}{l}\text { Argentinian hVP6 } \\
\text { sequence }\end{array}$ & $\begin{array}{l}\text { Human strains } \\
(\%)\end{array}$ & $\begin{array}{l}\text { Porcine strains } \\
(\%)\end{array}$ & $\begin{array}{l}\text { Bovine Strains } \\
(\%)\end{array}$ \\
\hline $\begin{array}{l}\text { Nucleotide } \\
\text { Amino acid }\end{array}$ & 97.9 & 75.9 & 74.6 \\
\hline
\end{tabular}

\section{Results}

\subsection{Analysis of the hRVC VP6 sequence}

The complete VP6 ORF sequence was amplified by PCR, cloned into the pGEM-T vector and its identity confirmed by sequencing. The obtained 1206 bp sequence (MF422080) was compared with 66 RVC VP6 sequences available in GenBank (32 human, 30 porcine and four bovine). Argentinian hRVC VP6 sequence clustered into genotype I2 (Fig. 1) with all human RVC strains (Baek et al., 2013; Jeong et al., 2015; Stipp et al., 2015; Suzuki et al., 2014; Yamamoto et al., 2011).

The nucleotide and amino acid evolutionary divergence were analyzed by comparing the obtained VP6 sequence with available RVC VP6 sequences from human, porcine and bovine origin (Table 1). The divergence was higher between the vp6 nucleotide sequences from different species (around 22\%) while for the amino acid sequences was around $10 \%$. The divergence within the human strains subgroup was lower than $3 \%$.

\subsection{Generation of HSV-hVP6C}

The hRVC VP6 coding sequence was subcloned from pGEM-T into pHSV under the control of the HSV-1 immediate-early (IE) 4/5 promoter, upstream of an internal ribosomal entry site (IRES) element of poliovirus followed by the enhanced green fluorescent protein (EGFP) coding sequence and the SV40 polyadenylation signal (Fig. 2).

The amplicon plasmid was co-transfected together with HSV-1 helper DNA into Vero 2-2 cells, and the recombinant amplicon vector stocks were collected $72 \mathrm{~h}$ post-transfection, producing a titer of $2.7 \times 10^{5} \mathrm{TU} / \mathrm{ml}$. RVC VP6 expression was evaluated by Western blot and immunofluorescence analyses.

Western blot analysis confirmed a reactive band with the expected molecular weight ( $44.7 \mathrm{kDa})$ in the protein extracts obtained from HSVhVP6C transduced cells (Fig. 3, lane 1) whereas no detectable reactivity was observed in protein extracts from uninfected cells or in extracts derived from cells infected with HSVs[MSP5] (unrelated HSV amplicon) (Palacios et al., 2014) (Fig. 3, lanes 2 and 3).

VP6 expression in amplicon vector-infected cells was also assessed by immunofluorescence. As shown in Fig. 4 (Merged column, VP6C row), the observed fluorescence pattern is mainly cytoplasmic with a strong signal near the nucleus. For comparison purposes, the obtained images were contrasted against images from cells transduced with a HSV-1 amplicon vector expressing RVA VP6 protein (HSV-hVP6A). The intracellular distribution of RVA VP6 presented a cytoplasmic fiber-like pattern Fig. 4 (Merged column, VP6A row) (Palacios et al., 2015), which is markedly different from that observed for RVC VP6. As expected, untransduced cells did not present any signal for VP6 or EGFP expression.

\subsection{Mouse humoral response to HSV-hVP6C}

The presence of specific anti-VP6 IgG was determined by EIA in sera obtained on days $0,28,42$ and 56 of mice immunized subcutaneously with HSV-hVP6C or PBS (control group). As shown in Fig. 5A, HSVhVP6C induced an hRVC-specific IgG response, in the absence of an adjuvant. An increase in anti-VP6 specific $\operatorname{IgG} \mathrm{OD}_{490}$ values was 


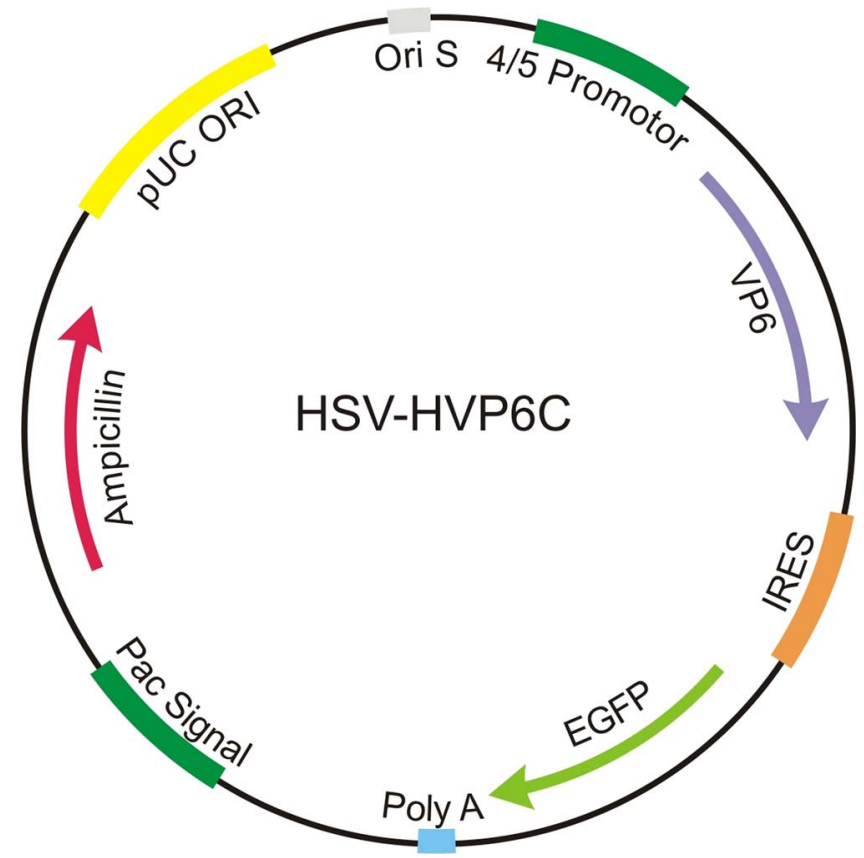

Fig. 2. Schematic representation of the HSV-hVP6C amplicon plasmid. The VP6 coding sequence is cloned downstream of the HSV-1 IE4/5 promoter (IE4/5 Prom) and upstream of a poliovirus internal ribosomal entry site (IRES), green fluorescent protein (EGFP) coding sequences, and an SV40 polyadenylation signal (Poly A). OriS and the pac Signal represent the HSV-1 sequences that support amplicon DNA replication and packaging into HSV-1 particles, respectively. The ampicillin resistance gene, as well as the colE1 replication origin, needed for prokaryotic propagation, are also depicted.

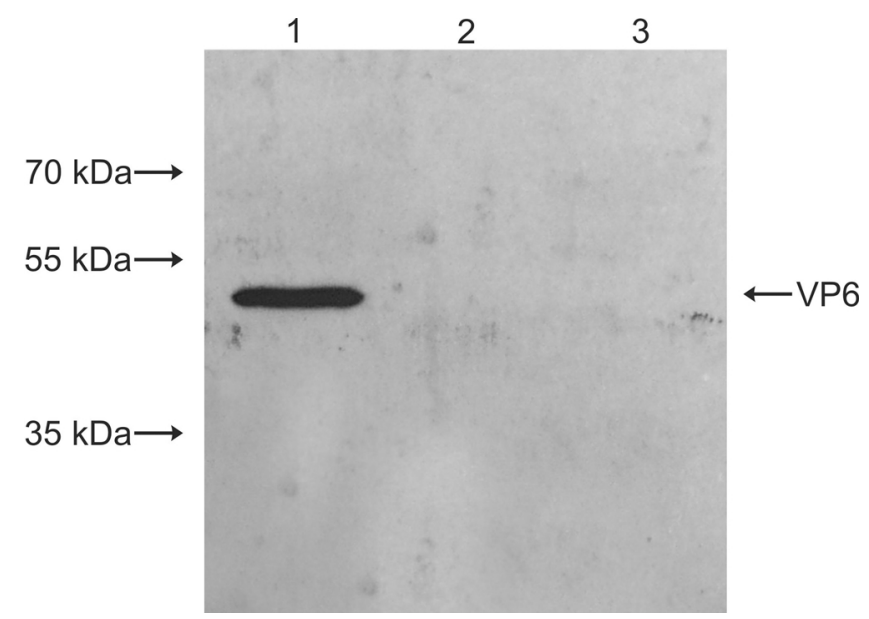

Fig. 3. Western blot analysis of total protein extracts. Protein suspension obtained from HSV-hVP6C infected cells (lane 1), uninfected cells (lane 2) and cells infected with the unrelated vector, HSVs[MSP5] (lane 3). The size of the molecular weight standards (kDa) and the VP6 band are indicated at the left and right of the membrane, respectively.

observed for all mouse sera after the second and third immunizations, evaluated at days 42 and 56, respectively. It is important to note that all mice in the group responded to the immunization (data not shown). The titer of specific IgG in the group immunized with HSV-hVP6C was significantly higher than the titer of the control group immunized with the empty amplicon vector (HSV-EGFP; Fig. 5B).

\section{Discussion}

In the present work, we constructed an HSV-1 amplicon vector encoding the hRVC VP6 protein. It is interesting to note that the cloned VP6 sequence was obtained from a local circulating hRVC strain which, when compared to other VP6 sequences, grouped with Indian, Russian and Spanish strains, within the human clade. We also analyzed the divergence of the obtained sequence with RVC VP6 from human, porcine and bovine strains. The comparison with other human strains sequences demonstrated a very low divergence among them (about 3\%), whereas divergence rates of about $10 \%$ were seen with their porcine and bovine counterparts. Although the divergence between human and porcine strains is not high, these small differences should be taken into account when designing a VP6-based immunogen to optimize its performance against hRVC.

HSV-1 based amplicon vectors have been described as efficient tools for gene transfer because of their large transgene capacity and their ability to efficiently transduce different mammalian cells (Santos et al., 2007). This large transgene capacity allowed the packaging of approximately 20 copies of the transgene cassette that included not only an hRVC VP6 coding sequence but also an IRES sequence and the EGFP coding sequence that facilitates titration of the vector stocks and monitoring transduced cells by fluorescence microscopy.

In this work, the VP6 protein was chosen as a model protein for the evaluation of HSV-1 vectors against hRVC for two main reasons. The first one, associated with the fact that VP6 protein is the most immunogenic and abundant in the virion; the second, in relation to what is known about RVA. For this group, several studies have pointed out that the VP6 protein confers protection against infection in some animal models, despite not inducing neutralizing antibodies. In particular, Jalilvand et al. (2015) have excellently summed up the main contributions of different groups that have worked with the VP6 protein of RVA as an immunogen. Also, recent publications have used VP6 protein as an immunogen proposed for vaccine development against RVA following different strategies (Feng et al., 2017; Afchangi et al., 2017). On the other hand, given the degree of sequence conservation observed within the same group, VP6 is an excellent candidate for an immunogen since it would be able to confer heterotypic protection.

Western blot analysis of protein extracts from HSV-hVP6C transduced cells using specific anti-RVC VP6 (Cowden strain) IgG revealed a unique band corresponding to the molecular weight of VP6, confirming the expression and identity of the recombinant protein. Furthermore, immunofluorescence analysis performed on transduced fixed cells also confirmed VP6 expression, revealing a cytoplasmic distribution pattern of the protein and a single perinuclear inclusion. As far as we know, this is the first report describing the intracellular distribution of the recombinant hRVC VP6 protein. It is worth mentioning that the observed protein distribution was quite different from that observed for RVA VP6 protein expressed in the same cell line following the same expression strategy. In this case, recombinant RVA VP6 presented tubular structures within the cytoplasm, similar to that observed when is expressed in insect cells where it can also assemble in different structures (trimers, spheres, and tubes) in vitro, depending on the $\mathrm{pH}$ and ionic strength conditions (Lepault et al., 2001). Similar results were obtained by Bugli et al. (2014), for a RVA VP6 protein expressed in Escherichia coli. Mena et al. (2006), confirmed the presence of tubular structures in vivo when RVA VP6 was expressed in High Five cell line and showed that the characteristic cytoplasmic distribution of VP6 was not due to an interaction between VP6 and microtubules. With HSV-1 amplicon strategy, we reproduced the reported tubular RVA VP6 intracellular distribution and showed that the distribution of RVC VP6 protein is different, which has not previously been reported.

RVA virions have been reported to be stable while RVC virions are fragile and unstable (Esona et al., 2008). It might be interesting to investigate whether the different properties of RVA and RVC VP6 proteins observed in HSV-1 amplicon vector transduced cells may be in some way related to this phenomenon which is beyond the scope of the present work.

HSV-1 based vectors have been described as promising candidates for the design of a new generation of genetic vaccines (Cuchet et al., 2007; Marconi et al., 2009). Notably, it has been reported that they can elicit both cellular and humoral immune responses that, in some cases, 

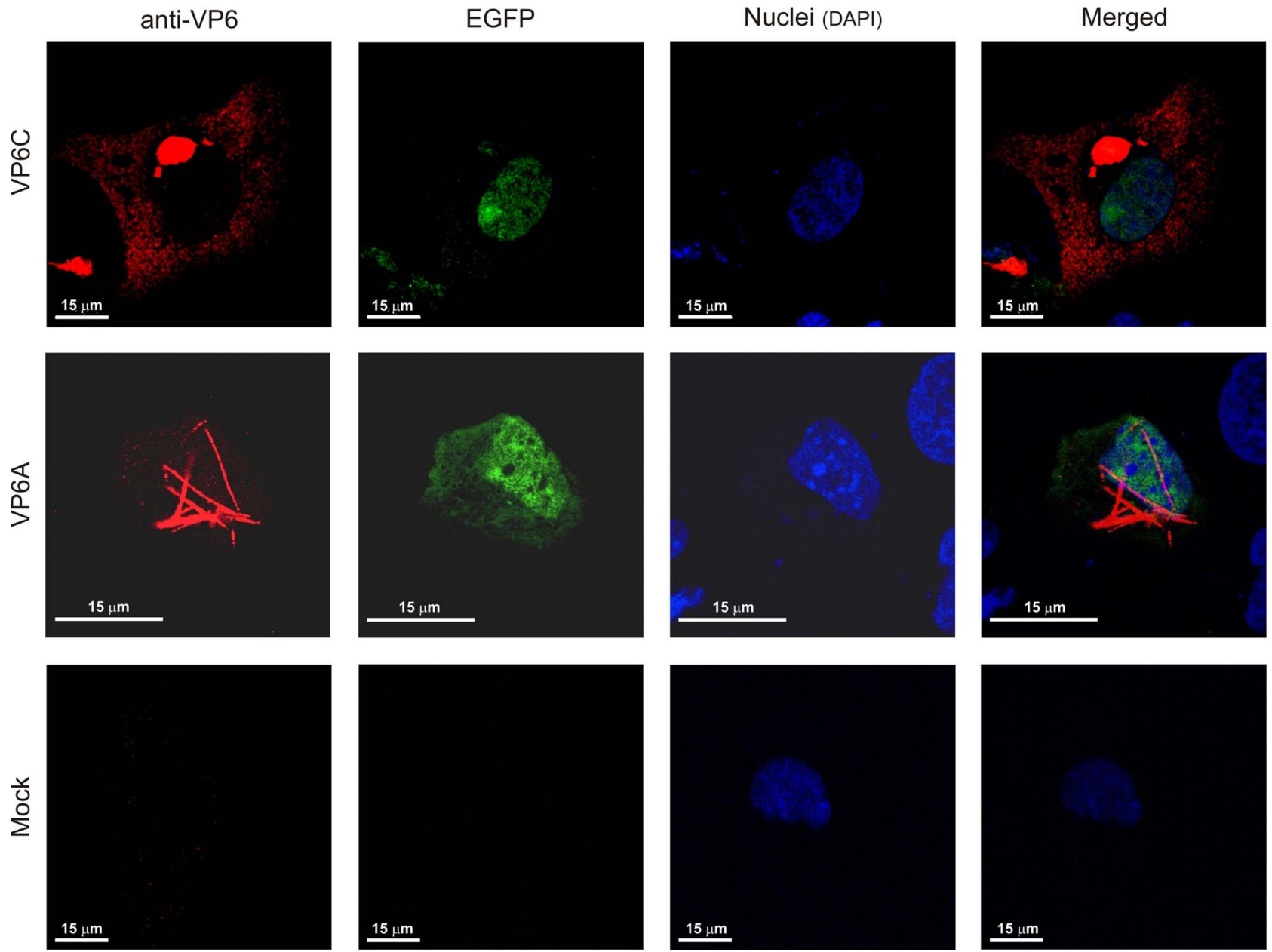

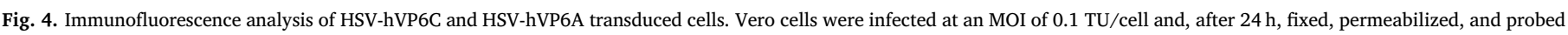

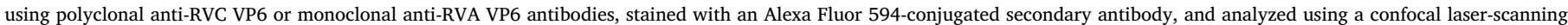
microscope. DAPI was used to visualize cell nuclei. Scale bar $=15 \mu \mathrm{m}$.

can persist for at least five months (D'Antuono et al., 2010; Laimbacher et al., 2012). Despite the fact that they have several characteristics that make them very efficient tools for delivering heterologous genes in vivo, some disadvantages have been mentioned. In an example, their production is based upon transfecting cells, making the scaling up process difficult, although the amplicon titers obtained are reasonable good.
Moreover, some authors have reported some instability in the gene expression (Sena-Esteves et al., 2000).

In this work, we analyzed the humoral immune response obtained when recombinant HSV-1 based amplicon vectors encoding hRVC VP6 protein were inoculated in mice in the absence of adjuvants. All the individuals within the immunized group produced specific antibodies
A

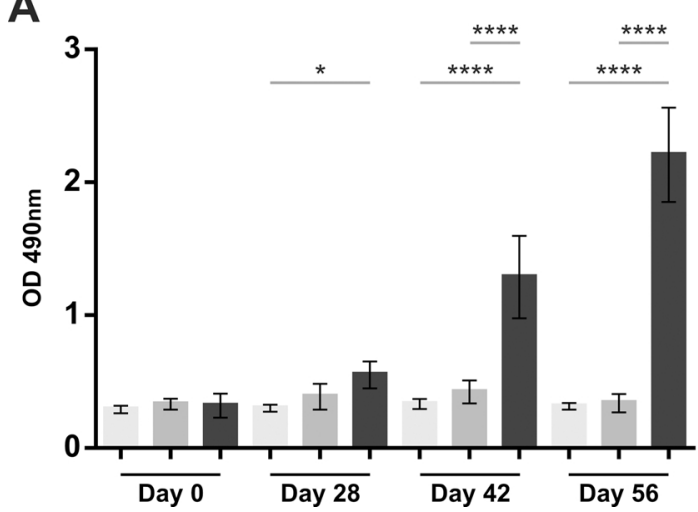

B

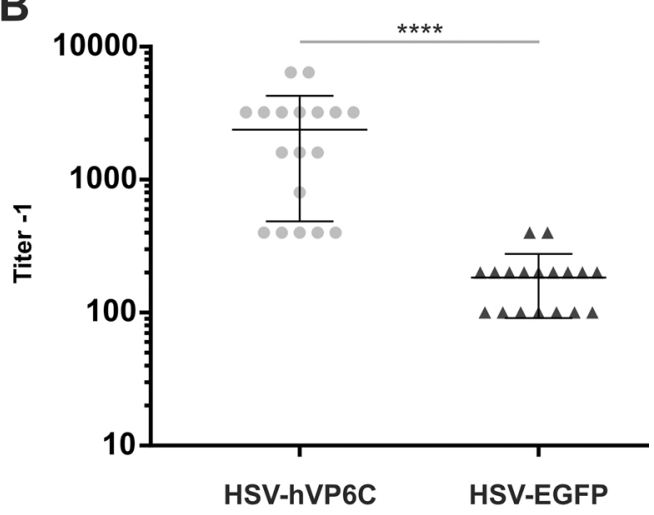

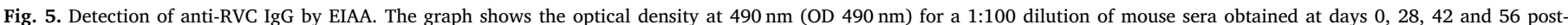

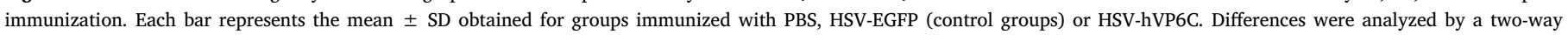

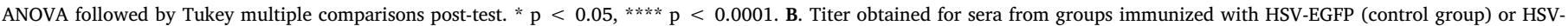

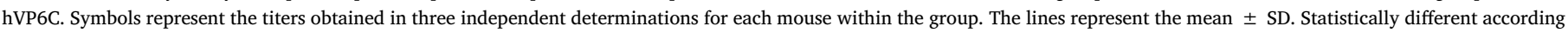
to a non-parametric t-test (Mann Whitney), ${ }^{* * *} \mathrm{p}<0.0001$. 
against hRVC, which markedly increased after each booster immunization.

Unfortunately, there is not an optimized animal model that can be used to evaluate whether the obtained immune response is effective at preventing hRVC infection or disease. Furthermore, a neutralization test would not help to assess whether the generated antibodies are capable of neutralizing viral infection, since VP6 forms the intermediate capsid of the viral particle and RVC does not grow correctly in cell cultures (Burns et al., 1996; Saif et al., 1988; Shinozaki et al., 1996; Tsunemitsu et al., 1991). Burns et al. (1996) demonstrated that antibodies directed against RVA VP6 are protective in vivo even though they lack neutralizing activity. Taking into account these results and that VP6 is the most conserved protein within RVC, the strategy proposed in this work would be an excellent option to induce an immune response against different hRVC strains circulating worldwide.

The low toxicity reported for these amplicon vectors, as well as their safety since they are replicative-deficient viruses, make HSV-1 based amplicons an interesting approach when designing an immunogen for human group $\mathrm{C}$ rotavirus with prophylactic purposes.

\section{Acknowledgements}

This work was partially supported by grants from Universidad Nacional de Quilmes and the Herpesvirus-based vaccines against Rotavirus infections (HEVAR) FP6 2004-INCO-DEV-3. Dr. Temprana C.F. is a member of the Argentine Research Council (CONICET). CONICET fellowships for Dr. Rota, R.P., Dr. Palacios C.A., and Dr. Mandile M.G. are also acknowledged.

\section{References}

Afchangi, A., Arashkia, A., Shahosseini, Z., Jalilvand, S., Marashi, S.M., Roohvand, F., Mohajel, N., Shoja, Z., 2017. Immunization of mice by rotavirus nsp4-VP6 fusion protein elicited stronger responses compared to VP6 alone. Viral Immunol. http://dx. doi.org/10.1089/vim.2017.0075.

Araújo, I.T., Heinemann, M.B., Fialho, A.M., Leite, J.P.G., 2011. Detection and molecular characterization of human group C rotavirus in Brazil. Intervirology 54, 261-267.

Argüielles, M.H., Villegas, Ga, Castello, A., Abrami, A., Ghiringhelli, P.D., Semorile, L., Glikmann, G., 2000. VP7 and VP4 genotyping of human group A rotavirus in Buenos Aires, Argentina. J. Clin. Microbiol. 38, 252-259.

Baek, I.H., Than, V.T., Kim, H., Lim, I., Kim, W., 2013. Full genomic characterization of a group C rotavirus isolated from a child in South Korea. J. Med. Virol. 85, 1478-1484.

Bucardo, F., Nordgren, J., 2015. Impact of vaccination on the molecular epidemiology and evolution of group A rotaviruses in Latin America and factors affecting vaccine efficacy. Infect. Genet. Evol. 34, 106-113.

Bugli, F., Caprettini, V., Cacaci, M., Martini, C., Paroni Sterbini, F., Torelli, R., Della Longa, S., Papi, M., Palmieri, V., Giardina, B., Posteraro, B., Sanguinetti, M., Arcovito, A., 2014. Synthesis and characterization of different immunogenic viral nanoconstructs from rotavirus VP6 inner capsid protein. Int. J. Nanomed. 9, 2727-2739.

Burns, J.W., Siadat-Pajouh, M., Krishnaney, A.A., Greenberg, H.B., 1996. Protective effect of rotavirus VP6-specific IgA monoclonal antibodies that lack neutralizing activity. Science 272, 104-107.

Castello, A.A., Argüelles, M.H., Rota, R.P., Humphrey, C.D., Olthoff, A., Gentsch, J.R. Glass, R.I., Glikmann, G., Jiang, B., 2009. Detection and characterization of group C rotavirus in Buenos Aires, Argentina, 1997-2003. J. Med. Virol. 81, 1109-1116.

Castello, A.A., Argüelles, M.H., Villegas, G.A., López, N., Ghiringhelli, D.P., Semorile, L. Glikmann, G., 2000. Characterization of human group C rotavirus in Argentina. J. Med. Virol. 62, 199-207.

Castello, A.A., Argüelles, M.H., Villegas, G.A., Olthoff, A., Glikmann, G., 2002. Incidence and prevalence of human group C rotavirus infections in Argentina. J. Med. Virol. 67, $106-112$.

Chang, K.O., Nielsen, P.R., Ward, La, Saif, L.J., 1999. Dual infection of gnotobiotic calves with bovine strains of group A and porcine-like group C rotaviruses influences pathogenesis of the group C rotavirus. J. Virol. 73, 9284-9293.

Clark, K.B., Lin, S.-C., Humphrey, C., Foytich, K., Esona, M., Wang, Y., Liu, M., Jiang, B., 2009. Expression and characterization of human group $C$ rotavirus virus-like particles in insect cells. Virology 387, 267-272.

Cuchet, D., Potel, C., Thomas, J., Epstein, A.L., 2007. HSV-1 amplicon vectors: a promising and versatile tool for gene delivery. Expert Opin. Biol. Ther. 7, 975-995.

D'Antuono, A., Laimbacher, A.S., La Torre, J., Tribulatti, V., Romanutti, C., Zamorano, P., Quattrocchi, V., Schraner, E.M., Ackermann, M., Fraefel, C., Mattion, N., 2010. HSV-1 amplicon vectors that direct the in situ production of foot-and-mouth disease virus antigens in mammalian cells can be used for genetic immunization. Vaccine 28, $7363-7372$

de Silva, S., Bowers, W.J., 2009. Herpes virus amplicon vectors. Viruses 1, 594-629.

Epstein, A.L., 2009. Progress and prospects: biological properties and technological advances of herpes simplex virus type 1-based amplicon vectors. Gene Ther. 16, $709-715$.

Esona, M.D., Humphrey, C.D., Dennehy, P.H., Jiang, B., 2008. Prevalence of group C rotavirus among children in Rhode Island, United States. J. Clin. Virol. 42, 221-224.

Estes, M.K., Greenberg, H.B., 2013. Rotaviruses. In: Knipe, D.M., Howley, P.M. (Eds.), Fields Virology. Wolters Kluwer Health/Lippincott Williams \& Wilkins, Philadelphia, PA, USA, pp. 1347-1395.

Feng, H., Li, X., Song, W., Duan, M., Chen, H., Wang, T., Dong, J., 2017. Oral administration of a seed-based bivalent rotavirus vaccine containing VP6 and NSP4 induces specific immune responses in mice. Front. Plant Sci. 8, 910. http://dx.doi.org/10. 3389/fpls.2017.00910.

Gabbay, Y.B., Borges, A.A., Oliveira, D.S., Linhares, A.C., Mascarenhas, J.D.P., Barardi, C.R.M., Simões, C.M.O., Wang, Y., Glass, R.I., Jiang, B., 2008. Evidence for zoonotic transmission of group C rotaviruses among children in Belém, Brazil. J. Med. Virol. $80,1666-1674$.

Ishimaru, Y., Nakano, H., Oseto, M., Yamashita, Y., Kobayashi, N., Urasawa, S., 1990. Group C rotavirus infection and infiltration. Acta Paediatr. Jpn. 32, 523-529.

Jalilvand, S., Marashi, S.M., Shoja, Z., 2015. Rotavirus VP6 preparations as a non-replicating vaccine candidates. Vaccine $33,3281-3287$.

Jeong, Y.-J., Matthijnssens, J., Kim, D.-S., Kim, J.-Y., Alfajaro, M.M., Park, J.-G., Hosmillo, M., Son, K.-Y., Soliman, M., Baek, Y.-B., Kwon, J., Choi, J.-S., Kang, M.-I., Cho, K.-O., 2015. Genetic diversity of the VP7, VP4 and VP6 genes of Korean porcine group C rotaviruses. Vet. Microbiol. 176, 61-69.

Jeong, Y.-J., Park, S.-I., Hosmillo, M., Shin, D.-J., Chun, Y.-H., Kim, H.-J., Kwon, H.-J., Kang, S.-Y., Woo, S.-K., Park, S.-J., Kim, G.-Y., Kang, M.-I., Cho, K.-O., 2009. Detection and molecular characterization of porcine group C rotaviruses in South Korea. Vet. Microbiol. 138, 217-224.

Karafillakis, E., Hassounah, S., Atchison, C., 2015. Effectiveness and impact of rotavirus vaccines in Europe, 2006-2014. Vaccine 33, 2097-2107.

Kim, Y., Chang, K., Kim, W., Saif, L.J., 2002. Production of hybrid double- or triplelayered virus-like particles of group A and C rotaviruses using a baculovirus expression system. Virology 302, 1-8.

Laimbacher, A.S., Esteban, L.E., Castello, A.A., Abdusetir Cerfoglio, J.C., Argüelles, M.H., Glikmann, G., D’Antuono, A., Mattion, N., Berois, M., Arbiza, J., Hilbe, M., Schraner, E.M., Seyffert, M., Dresch, C., Epstein, A.L., Ackermann, M., Fraefel, C., 2012. HSV-1 amplicon vectors launch the production of heterologous rotavirus-like particles and induce rotavirus-specific immune responses in mice. Mol. Ther. 20, 1810-1820.

Laimbacher, A.S., Fraefel, C., 2014. HSV-1 amplicon vectors as genetic vaccines. In: Diefenbach, R.J., Fraefel, C. (Eds.), Herpes Simplex Virus. pp. 99-115.

Larkin, M.A., Blackshields, G., Brown, N.P., Chenna, R., McGettigan, P.A., McWilliam, H., Valentin, F., Wallace, I.M., Wilm, A., Lopez, R., Thompson, J.D., Gibson, T.J., Higgins, D.G., 2007. Clustal W and Clustal X version 2.0. Bioinformatics 23, 2947-2948.

Lepault, J., Petitpas, I., Erk, I., Navaza, J., Bigot, D., Dona, M., Vachette, P., Cohen, J., Rey, F.A., 2001. Structural polymorphism of the major capsid protein of rotavirus. EMBO J. 20, 1498-1507.

Luchs, A., do Carmo Sampaio Tavares Timenetsky, M., 2014. Phylogenetic analysis of human group C rotavirus circulating in Brazil reveals a potential unique NSP4 genetic variant and high similarity with Asian strains. Mol. Genet. Genom. 290, 969-986.

Marconi, P., Argnani, R., Epstein, A.L., Manservigi, R., 2009. HSV as a vector in vaccine development and gene therapy. Adv. Exp. Med. Biol. 655, 118-144.

Marton, S., Deák, J., Dóró, R., Csata, T., Farkas, S.L., Martella, V., Bányai, K., 2015a. Reassortant human group C rotaviruses in Hungary. Infect. Genet. Evol. 34, 410-414.

Marton, S., Mihalov-Kovács, E., Dóró, R., Csata, T., Fehér, E., Oldal, M., Jakab, F., Matthijnssens, J., Martella, V., Bányai, K., 2015b. Canine rotavirus C strain detected in Hungary shows marked genotype diversity. J. Gen. Virol. 96, 3059-3071.

Matthijnssens, J., Ciarlet, M., Rahman, M., Attoui, H., Bányai, K., Estes, M.K., Gentsch, J.R., Iturriza-Gómara, M., Kirkwood, C.D., Martella, V., Mertens, P.P.C., Nakagomi, O., Patton, J.T., Ruggeri, F.M., Saif, L.J., Santos, N., Steyer, A., Taniguchi, K., Desselberger, U., Van Ranst, M., 2008. Recommendations for the classification of group A rotaviruses using all 11 genomic RNA segments. Arch. Virol. 153, 1621-1629.

Matthijnssens, J., Otto, P.H., Ciarlet, M., Desselberger, U., van Ranst, M., Johne, R., 2012. VP6-sequence-based cutoff values as a criterion for rotavirus species demarcation. Arch. Virol. 157, 1177-1182.

Mena, J.A., Ramírez, O.T., Palomares, L.A., 2006. Intracellular distribution of rotavirus structural proteins and virus-like particles expressed in the insect cell-baculovirus system. J. Biotechnol. 122, 443-452.

Nilsson, M., Sigstam, G., Svensson, L., 2000. Antibody prevalence and specificity to group C rotavirus in Swedish sera. J. Med. Virol. 60, 210-215.

De Oliveira, A.P., Glauser, D.L., Laimbacher, A.S., Strasser, R., Schraner, E.M., Wild, P., Ziegler, U., Breakefield, X.O., Ackermann, M., Fraefel, C., de Oliveira, A.P., Glauser, D.L., Laimbacher, A.S., Strasser, R., Schraner, E.M., Wild, P., Ziegler, U., Breakefield, X.O., Ackermann, M., Fraefel, C., 2008. Live visualization of herpes simplex virus type 1 compartment dynamics. J. Virol. 82, 4974-4990.

Otto, P.H., Rosenhain, S., Elschner, M.C., Hotzel, H., Machnowska, P., Trojnar, E., Hoffmann, K., Johne, R., 2015. Detection of rotavirus species A, B and C in domestic mammalian animals with diarrhoea and genotyping of bovine species A rotavirus strains. Vet. Microbiol. 179, 168-176.

Palacios, C.A., Claus, J., Mattion, N., 2015. Rotavirus VP6 protein expressed in cell culture by HSV-1-based vectors. Rev. Argent. Microbiol. 47, 80-81.

Palacios, C., Torioni de Echaide, S., Mattion, N., 2014. Evaluation of the immune response to Anaplasma marginale MSP5 protein using a HSV-1 amplicon vector system or recombinant protein. Res. Vet. Sci. 97, 514-520.

Patton, J.T., 2012. Rotavirus diversity and evolution in the post-vaccine world. Discov. Med. 13, 85-97. 
Peixoto, C., Sousa, M.F.Q., Silva, A.C., Carrondo, M.J.T., Alves, P.M., 2007. Downstream processing of triple layered rotavirus like particles. J. Biotechnol. 127, 452-461.

Saeki, Y., Fraefel, C., Ichikawa, T., Breakefield, X.O., Chiocca, E.A., 2001. Improved helper virus-free packaging system for HSV amplicon vectors using an ICP27-deleted, oversized HSV-1 DNA in a bacterial artificial chromosome. Mol. Ther. 3, 591-601.

Saif, L.J., Terrett, L.A., Miller, K.L., Cross, R.F., 1988. Serial propagation of porcine group $\mathrm{C}$ rotavirus (pararotavirus) in a continuous cell line and characterization of the passaged virus. J. Clin. Microbiol. 26, 1277-1282.

Sambrook, J., Fritsch, E.F., Maniatis, T., 1989. Molecular Cloning: A Laboratory Manual, 3rd ed. Cold Spring Harbor Laboratory Press, Cold Spring Harbor, New York.

Santos, K., Simon, D.A.L., Conway, E., Bowers, W.J., Mitra, S., Foster, T.H., Lugade, A., Lord, E.M., Federoff, H.J., Dewhurst, S., Frelinger, J.G., 2007. Spatial and tempora expression of herpes simplex virus type 1 amplicon-encoded genes: implications for their use as immunization vectors. Hum. Gene Ther. 18, 93-105. http://dx.doi.org/ 10.1089/hum.2006.082.

Sena-Esteves, M., Saeki, Y., Fraefel, C., Breakefield, X.O., 2000. HSV-1 amplicon vectorssimplicity and versatility. Mol Ther. 2, 9-15.

Shinozaki, K., Yamanaka, T., Tokieda, M., Shirasawa, H., Simizu, B., 1996. Isolation and serial propagation of human group $\mathrm{C}$ rotaviruses in a cell line (CaCo-2. J. Med. Virol. $48,48-52$.

Smith, I.L., Hardwicke, M.A., Sandri-Goldin, R.M., 1992. Evidence that the herpes simplex virus immediate early protein ICP27 acts post-transcriptionally during infection to regulate gene expression. Virology 186, 74-86.

Steele, A.D., James, V.L.A., 1999. Seroepidemiology of human group C rotavirus in South
Africa. J. Clin. Microbiol. 37, 4142-4144.

Stipp, D.T., Alfieri, A.F., Lorenzetti, E., da Silva Medeiros, T.N., Possatti, F., Alfieri, A.A. 2015. VP6 gene diversity in 11 Brazilian strains of porcine group C rotavirus. Virus Genes 50, 142-146.

Suzuki, T., Hasebe, A., Miyazaki, A., Tsunemitsu, H., 2014. Phylogenetic characterization of VP6 gene (inner capsid) of porcine rotavirus C collected in Japan. Infect. Genet. Evol. 26, 223-227.

Tamura, K., Stecher, G., Peterson, D., Filipski, A., Kumar, S., 2013. MEGA6: Molecular Evolutionary Genetics Analysis version 6.0. Mol. Biol. Evol. 30, 2725-2729.

Tiku, V.R., Jiang, B., Kumar, P., Aneja, S., Bagga, A., Bhan, M.K., Ray, P., 2017. First study conducted in Northern India that identifies group C rotavirus as the etiological agent of severe diarrhea in children in Delhi. Virol. J. 14, 100.

Tsunemitsu, H., Saif, L.J., Jiang, B., Shimizu, M., Hiro, M., Yamaguchi, H., Ishiyama, T, Hirai, T., 1991. Isolation, characterization, and serial propagation of a bovine group C rotavirus in a monkey kidney cell line (MA104). J. Clin. Microbiol. 29, 2609-2613.

Vlasova, A.N., Amimo, J.O., Saif, L.J., 2017. Porcine rotaviruses: epidemiology, immune responses and control strategies. Viruses 9, 1-27.

Wakuda, M., Ide, T., Sasaki, J., Komoto, S., Ishii, J., Sanekata, T., Taniguchi, K., 2011. Porcine rotavirus closely related to novel group of human rotaviruses. Emerg. Infect. Dis. 17, 1491-1493.

Yamamoto, D., Ghosh, S., Kuzuya, M., Wang, Y., Zhou, X., Chawla-Sarkar, M., Paul, S.K., Ishino, M., Kobayashi, N., 2011. Whole-genome characterization of human group C rotaviruses: identification of two lineages in the VP3 gene. J. Gen. Virol. 92, 361-369. 